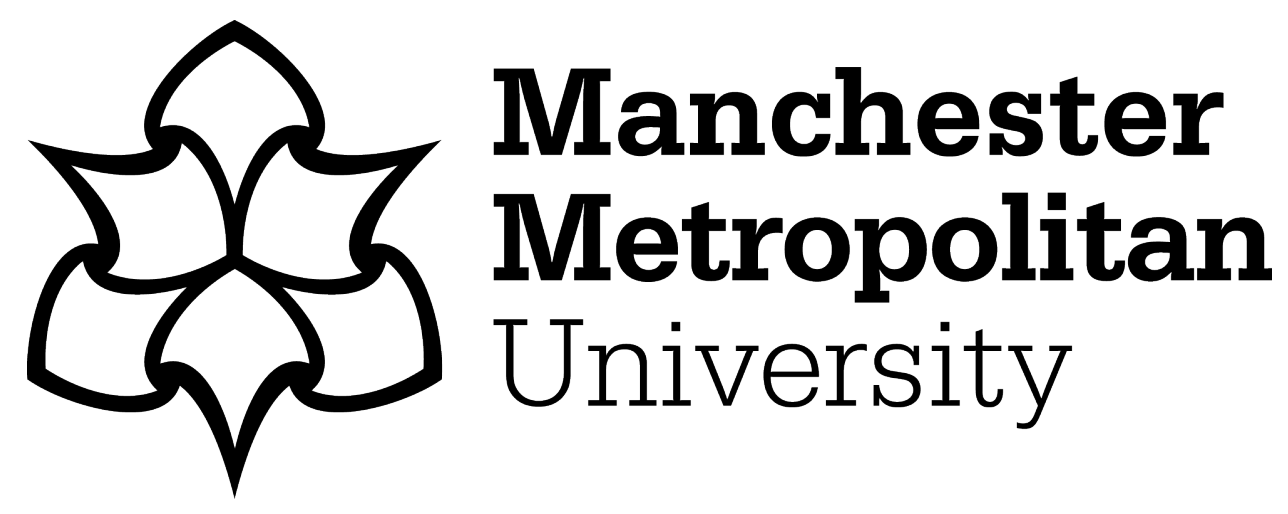

Aljameel, Sumayh, O'Shea, James, Crockett, KA ORCID logoORCID: https://orcid.org/0000-0003-1941-6201 and Latham, Annabel ORCID logoORCID: https://orcid.org/0000-0002-8410-7950 (2018) Can LANA CITS Support Learning in Autistic Children? A case study evaluation. In: Intelligent Systems and Applications Proceedings of the 2018 Intelligent Systems Conference (IntelliSys) Volume 2, 06 September 2018 - 07 September 2018, London, UK.

Downloaded from: https://e-space.mmu.ac.uk/620505/

Version: Accepted Version

Publisher: Springer

DOI: https://doi.org/10.1007/978-3-030-01057-7

Please cite the published version 


\title{
Can LANA CITS Support Learning in Autistic Children? A case study evaluation
}

\author{
Sumayh S. Aljameel, James D. O'Shea, Keeley A. Crockett, Annabel Latham \\ Department of Computing, Math and Digital Technology \\ Manchester Metropolitan University \\ sumayh.s.aljameel@ stu.mmu.ac.uk, \{j.d.oshea, k.crockett, a.latham\}@mmu.ac.uk
}

\begin{abstract}
LANA CITS is a Conversational Intelligent Tutoring System that uses the Visual, Auditory, and Kinaesthetic learning style (VAK). It supports learning in autistic pupils, who are studying in mainstream primary schools. Facilitating the learning of these pupils using traditional teaching within mainstream schools is complex and poorly understood. This paper present investigation into how LANA CITS using VAK learning style model can adapt to autistic pupils learning style and improve their learning in mainstream schools. This paper provides a case study evaluation of three children with high-functioning autism examining the effectiveness of learning with LANA CITS. The case study took place in primary school in Saudi Arabia. The results were positive with the students engaged in the tutorial and the teacher noticed some improvement over classroom activities. This results support for the continuing development, evaluation, and use of CITS for pupils with autism in mainstream schools.
\end{abstract}

Keywords - Intelligent Tutoring System; Autism Spectrum Disorder; Conversational Agent; VAK learning style.

\section{INTRODUCTION}

Pupils with Autism Spectrum Disorder (ASD) are affected in different degrees in terms with their level of intellectual ability. Some people with Asperger syndrome or high functioning autism are very intelligent academically but they still have difficulties in social and communication skills [1]. In recent years, many of these pupils are taught within mainstream schools. However, the process of facilitating their learning and participation remains a complex and poorly understood area of education [2, 3]. Many teachers in mainstream schools encourage the principles of inclusive education, but they do not feel that they have the enough training to teach autistic pupils $[4,5]$. Many pupils with ASD tend to be affected differently as a result of the same symptoms, so it is important to know how each child is impacted on in terms of their cognitive and interaction abilities. Hence, the specific requirements of each child, which is known as learning style, should be identified [6]. Pupils with ASD are more likely to rely on one style of learning, which could be determined by observing the person [7]. VAK theory is considered to be one of the classical learning theories in the educational field [8]. It classifies learners by sensory preferences: Visually (V), Auditory (A), and Kinaesthetic (K)[9]. Many researches [10-12] found that many people with autistic spectrum are visual learners as they can learn well through watching videos, pictures and movies. Another study
[13] found that Autistic people have learning preferences of kinaesthetic, visual, then auditory. Roberts [14] found that people with autism who are kinaesthetic learners, learn better when include "hands-on" activities with the teacher taught material to achieve learning. Nevertheless, research that has been conducted with autistic children regarding the impact of learning style is limited and need further research.

Technologies have attracted increasing attention in the autism community for their educational [15-17]. Several studies [18, 19] reported that the majority of people with autism feel positive towards technology and computer-based training. This is attributable to the fact that software programs offer a structured and predictable environment, which accommodates the autistic children preferences for routine and repetitive behaviours [20]. Truong [21] reviewed 51 studies of the recent applications which examined the integration of learning styles theories in adaptive learning system. In this review, it reported a positive impact of adaptive systems using learning styles on students satisfaction. No known intelligent tutoring system using the VAK learning style model has been specific developed for autistic children.

This paper is a part of our investigation within LANA CITS project [22, 23]. This project examines the research and development of a novel Arabic conversational intelligent tutoring system (CITS) for children with autism spectrum disorder (ASD) using the Visual, Auditory and Kinaesthetic learning styles model (VAK). The project aims to design and implement an Arabic CITS for children with autism aged 10-16 using the (VAK) model. The CITS architecture used the pattern matching (PM) and the Arabic short text similarity (STS) to extract the responses from resources in particular domain (Science subjects). This paper presents a case study evaluation of LANA CITS used by three pupils with high-functioning autism or Asperger's, who are studying in mainstream schools in Saudi Arabia. The case study approach was chosen for this study because characteristics of pupils with ASD differ widely from each other. In addition, large groups of pupils with ASD who have similar characteristics are difficult to recruit. The case study examines the effectiveness of using LANA CITS and whether the autistic pupils satisfied with the usability of LANA CITS. The main contribution of this paper is that it is the first case study evaluation of CITS using VAK model for pupils with high functioning autism in mainstream schools. This paper is 
organised as follows: Section II provides a brief overview of LANA CITS. Section III describes the case study methodology. Section IV presents the results and discussion and Section V the conclusion.

\section{LANA CONVERSATIONAL INTELLIGENT TUTORING SYSTEM}

\section{A. Background}

Conversational Intelligent Tutoring Systems (CITS) provide a natural language interface to an online tutoring system to allow users to learn topics through discussion as they would in the classroom. Many researchers have developed CITS for different domains, such as AutoTutor [24] which is a computer tutor that is designed to assist students within university to learn an introductory computer literacy course. However, AutoTutor does not consider the student learning styles during a tutoring session. Oscar [25] is another example of CITS, which overcomes AutoTutors limitation by predicting and adapting dynamically to a student's learning style. Oscar is developed for students in University's level and teaches SQL course. In the Arabic language, CITS is considered as a new area of research. Abdullah CITS [26] is a recent of Arabic CITS for modern Islamic education. Abdullah CITS is an online system that aims to teach children aged 10 to 12 years old essential topics in Islam. Abdullah CITS does not consider the student learning styles. To our knowledge, no academic research exists on the Arabic conversational intelligent tutoring system for Autistic children.

\section{B. LANA CITS}

LANA CITS [22] [23] is a novel Arabic CITS, which delivers topics related to the science subject by engaging with the user in Arabic language. LANA uses Visual, Auditory, and Kinaesthetic (VAK) learning style model to personalise the lesson according to the user learning style preference. The main feature of LANA CITS are:

- Ability to control the conversation through context. The domain used to script the CA was from the Science curriculum for the age (10-12 years old). The material was provided by the Ministry of Education in Saudi Arabia [27]. Scripts consisting of a context structured according to the topics in the science book such as the Earth, Moon, Solar System, eclipse, etc.).

- Ability to personalise the lesson with the user's learning style (VAK) and provide suitable material to the user according to the user's learning style (images and videos for Visual learner, Sound for Auditory learner, physical models for Kinaesthetic learner).

- A conversation agent scripting language, which provides Arabic dialogue for LANA CITS allowing capturing variables from the user utterance.

- A novel conversation agent engine using the pattern matching (PM) technique was first used to find a suitable response to the user's utterance. If it is not found, the engine uses the Short Text Similarity (STS) technique to find a response. Combining the techniques is beneficial to reduce the number of scripted patterns.

Figure 1 shows a screenshot of the conversation interface of LANA CITS, where the system converses with the student by asking him/her a question about a specific science topic and then providing the suitable response based on the student's utterance.

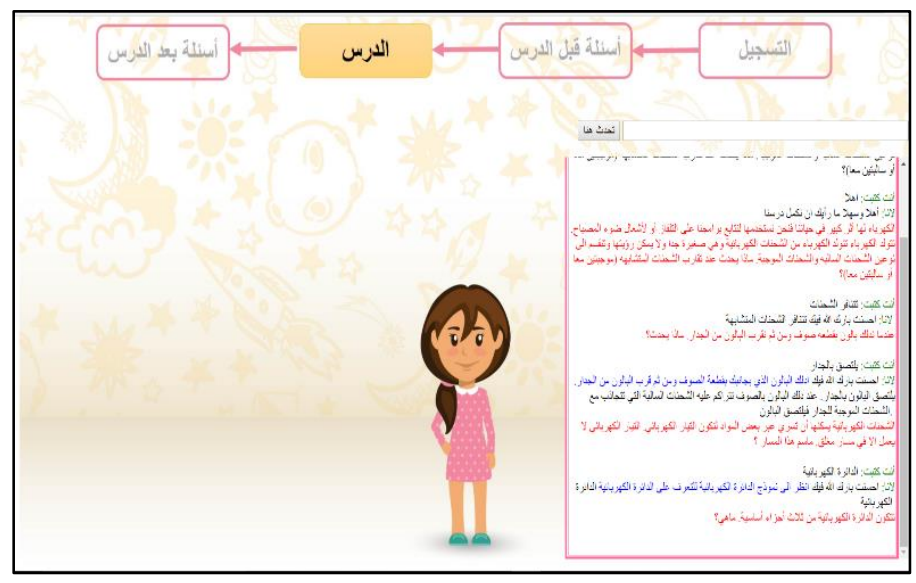

Fig. 1. LANA CITS graphics user interfaces.

\section{CASE STUdy}

This section presents the case study, which took place in a primary school in Saudi Arabia. Ethical informed consent was obtained from all participants, parents and the School. The study aims to test hypothesis H1 (LANA CITS can support learning in autistic children).

\section{A. Participants}

In this study, three participants who met the following criteria were interviewed and observed:

- Participant with age group (10-12) years old.

- $\mathrm{He} / \mathrm{she}$ had previously received a community clinical diagnosis of high functioning autism spectrum disorder or Asperger's, indicating that they have no problem with language and intellectual impairments.

- His/her first language was Arabic.

- Studying in mainstream primary schools in Saudi Arabia.

- No previous experience using LANA CITS.

To ensure data privacy, the names of participants have been changed in this paper. In this study, three autistic students are involved and all of them are female (Mariam, Fatimah, and Dana). Two of them (Mariam and Fatimah) are in (Grade 5), and their age is 11 years old, the third students (Dana) is in (Grade 4) and her age is 10 years old. The three participants are studying in mainstream primary school, which provided educational provision for children with ASD in Saudi Arabia. All three participants have Arabic as their first language and none of them had a previous experience using LANA CITS. Each child had previously received a community clinical diagnosis of Asperger's, who they have no problem with language and intellectual impairments. 


\section{B. Ethical Considerations}

Because the participants were children, an informed consent form and information sheet were sent to the participant's parents and the School. The information sheet outlined the details and purpose of the study, and the benefits for participating in the study. They also informed that the information gathered from the participant is stored securely and none of children's real names will be recorded.

\section{Data Collection Methods}

There are several data collections methods in qualitative research. Marshall and Rossman [28] identified three primary methods that qualitative researchers use for gathering information. Primary methods involve gathering information from the source directly. These three methods are: 1) participating in the setting, 2) observing directly, and 3) interviewing in depth. In this study, two primary methods are used: Observation and Interviewing. "Observation involves the systematic noting and recording of events, behaviors, and artifacts in the social setting," [28]. Kvale and Brinkman [29] defined the interview as a conversation with structure and a purpose. There are secondary methods that may also be used to gather information. This involves gathering information from someone or something else outside of the original source by analysing documents such as: videos, photography, interaction analysis, and questionnaires [28].

\section{Interviewing}

Interviewing is a universal methods in qualitative research [30, 31]. Interviews are typically divided into three categories: structured, unstructured, and semi-structured [32]. In structured interviews, all participants will have the same questions using the same wording and in the same order [33]. However, while a structured interview ensures that comparable responses are gathered from each participant, it leaves no room for elaboration [34]. The second category is an unstructured interview, which contains open questions and subsequent questions depending on the participant's responses[35]. The drawbacks of this type of interview are the difficulty of processing data and the effort required. It is difficult to find similar statements from different participants and hence the links are often difficult to make. The most common type of interviews used in qualitative research are the third category, which is semi-structured interviews. It involves structured questions and the researcher is free vary the order and wording of the questions [32], depending on the direction of the interview, and to ask additional questions. According to Berg [34], the researcher is able to adjust the wording of the questions, and add or delete probes, as necessary. With this structure, the interviewer guided the interview, to obtain a good description from the participant's perspective. Moreover, this structure allowed the researcher the flexibility to dive deeper when appropriate. Creswell [36] asserted that the semistructured process lets the researcher to explore and ask followup questions if necessary to clarify the particular subject. This was an extremely beneficial process in the field of qualitative interviewing.
The Semi-structured interviewing was used in this study because the participants are children and the level of comprehension may vary. The interview was interactive and the participants were able to ask questions. In addition, notes were taken during the interview to capture the core of the participant's comments and to note any non-verbal behaviour and facial expressions. In this study, two interviews were conducted for each student, the first interview was with the autistic student and the second interview was with the teacher. The first interview, which was with the autistic student, contains of nine questions and the interviewer was free to ask follow-up questions. Table 1 shows the nine questions that are used in the interview. The questions were asked in Arabic.

TABLE I. THE INTERVIEW SHEET WITH THE AUTISTIC STUDENT.

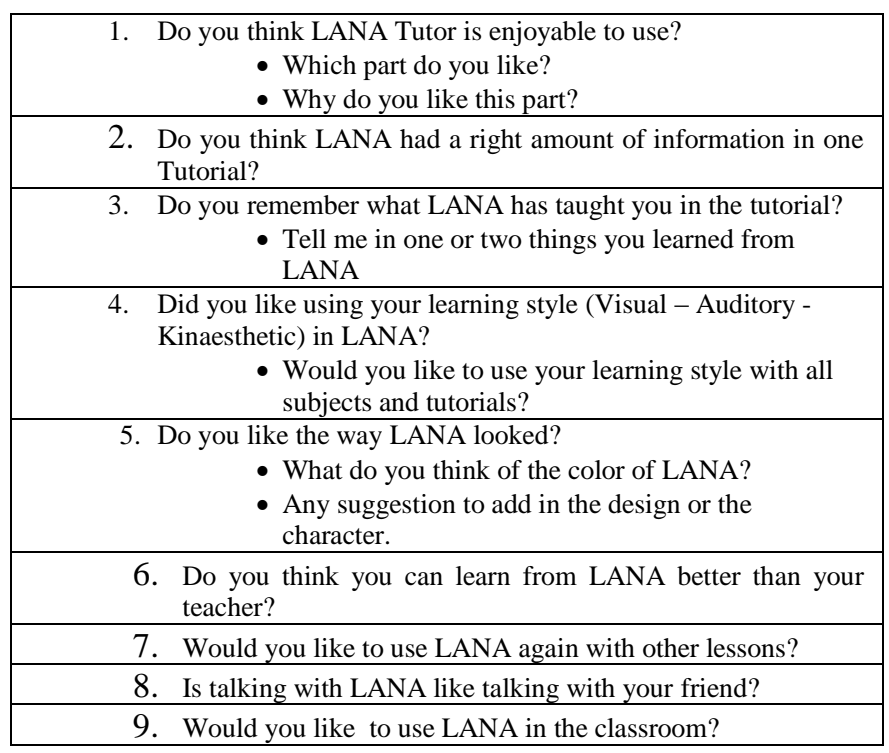

The second interview was conducted with the teacher. The aim of this interview is to measure the student's interaction and behaviour from the teacher's point of view. The interview contains five questions as shown in Table 2.

TABLE II. THE INTERVIEW SHEET WITH THE TEACHER.

\begin{tabular}{|cl|}
\hline 1. & Is there any behavioural issue with the student? \\
\hline 2. & What is the student's education level in the school? \\
\hline 3. & How was the student's interaction during the tutorial? \\
\hline 4. & $\begin{array}{l}\text { Did the student interact with the LANA's tutorial in the same } \\
\\
\text { way as the class tutorial? }\end{array}$ \\
\hline 5. & Do you have any suggestions to add to LANA? \\
\hline
\end{tabular}

\section{Participant Observation}


In addition to semi-structured interviews, the participant has been observed during the interview by Sumayh, the lead researcher of this study. Observations allow the interviewer to observe the context in which the participants interact [36]. Additionally, observations allow the researcher to notice the participant's behaviors, facial expressions, and the interactions.

\section{Data Analysis}

Following the interviews the data was analysed using the

following methodology [36].

1. Data management: This involves organizing and gathering all the data. In this study, the interview was transferred into a written format.

2. Reading and noting: This involves reading through all the transcriptions and making notes in the margins regarding the interviewee's comments.

3. Describing: This involves describing the participant's experience with the study.

4. Classifying: The researcher then makes a list of significant statements, quotes that emerged from the data and then grouped together.

5. Interpreting: the researcher develops textural and structural descriptions of the data. Textural descriptions are the written descriptions of what the participants experienced. After the textural descriptions are written, the researcher outlined the contextual influence, and this is the structural description.

6. Representing and visualizing: After both the textual and structural descriptions are written, the researcher writes the findings of the study. In addition, tables will be created to help illustrate the data.

\section{E. Participant's interaction}

The study started by detecting the participant's learning style using a child friendly-customised VAK learning style preferences questionnaire, which was answered by the student with the help of the teacher. The LANA CITS registration interface was then shown to the participant and the lead researcher registered the participant with her learning style into the system in order to adapt the tutorial according to her learning style. Then, a pre-test interface started (see Figure 2) and the participant was asked to complete the pre-test by choosing the right answer using the touch screen. When the pretest was completed, the tutorial started and the participant interacted with the tutorial and answered the questions related to the science subject. During the tutorial, materials were used according to the learning style (Visual: video and images, Auditory: sounds, Kinaesthetic: physical models). After the participant completed the tutorial, a post-test interface started and the participant answered the questions in the post-test. When the tutorial was completed a verbal interview (see Table 1) was conducted in order to measure the participant satisfaction and their opinion about using LANA CITS. During the tutorial and the interview, the student was observed by the lead researcher and the teacher to notice the participant's behaviors, facial expressions, and the interactions. Support was provided to the participant if asked. When the student finished and left the room, the teacher was interviewed by the lead researcher (see Table 2).

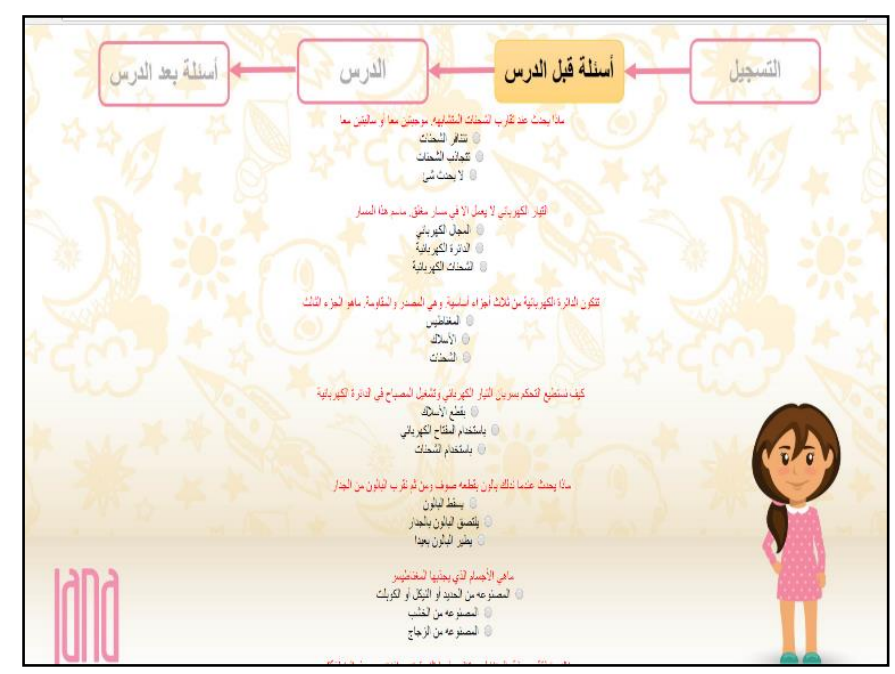

Fig. 2. Pre-test Questions interface.

\section{RESULTS AND DISCUSSION}

In this section, the data that was gathered from the interviews (Table 1, Table 2) and the observation were described and classified in order to test Hypothesis H1 (LANA CITS can support learning in autistic children).

\section{A. First participant Results and discussion}

Mariam: The first participant interviewed in this study, was Mariam. She is eleven years old in Grade 5 and she has an early community clinical diagnosis of Asperger's, with no problem with language and intellectual impairments. Based on the teacher's interview, Mariam made an improvement in her behaviour during her study in the school from Grade 1 to 5 . Her education level is very good especially in Maths and English. She is interested in using technology such as a computer, IPad, and mobile devices. The study begun by detecting Mariam's learning style using the questionnaire. The results from the questionnaire showed that her learning style was Visual. Mariam completed the pre-test and then interacted with the tutorial and answered the questions. During the tutorial, videos/images appeared for each information in the tutorial (see Figure 3). After she completed the tutorial, a post-test interface started and she answered the questions in the post-test. Mariam enjoyed using LANA CITS as indicated in her interview answers. She said that she especially liked watching the videos and the pictures during the tutorial. She was able to use LANA CITS independently with ease and required no additional support once told in how to use it. Her learning gain was improved when comparing the pre-test and the post-test scores. Table 3 shows the pre-test and the post test scores for all three participants. She was able to remember what she had learned from LANA, when she was asked in the interview. The rest of the interview questions were positive but when she was asked if she like learning from LANA CITS more than learning from her teacher, she answered 'Maybe'. 


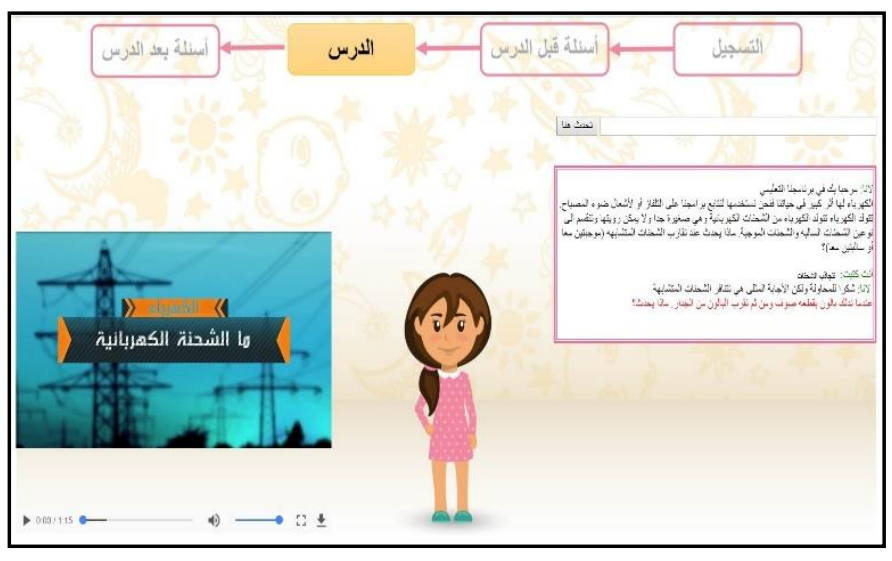

Fig. 3. The tutorial screenshot for the visual learner.

\section{B. Second participant Results and discussion}

Fatimah: The second participant interviewed in this study was Fatimah. She is eleven years old in Grade 5 and she had a late diagnosis of Asperger's, when she was nine years old. Based on the teacher's interview, Fatimah's education level is below the average because she does not like to study although she has an excellent memory. She has the ability to remember everything she has seen or read. Her learning style was detected using the questionnaire and it was found that her learning style was Visual. Fatimah completed the pre-test and then interacted with the tutorial and answered the questions. When she completed the tutorial, a post-test interface started and she answered the questions in the test. Fatimah said that using LANA CITS was very enjoyable. She liked watching to the videos and the pictures during the tutorial. She was using LANA CITS independently and easily with no additional support once she was told in how to use it. According to her scores in pre-test and post-test (Table 3), her learning gain was improved the post-test score was grater that the pre-test score. She was able to remember what she has been learned from LANA, when she was asked in the interview. When she was asking if she like learning from LANA CITS more than learning from her teacher, she answered 'Both'. The rest of the questions were answered positively.

\section{Third participant Results and discussion}

Dana: The third participant interviewed in this study was Dana. She is ten years old in Grade 4 and she also had a late diagnosis of Asperger's, when she was nine years old. Based on the teacher's interview, Dana's education level is above the average. She is very good student in all subjects. Her learning style was detected using the questionnaire and it was found that her learning style was Kinaesthetic so she used physical models within the tutorial. Dana completed the pre-test and then interacted with the tutorial. Figure 4 shows how the kinaesthetic learner interacts with the tutorial using physical model. When she completed the tutorial, a post-test interface started and she answered the questions in the test.

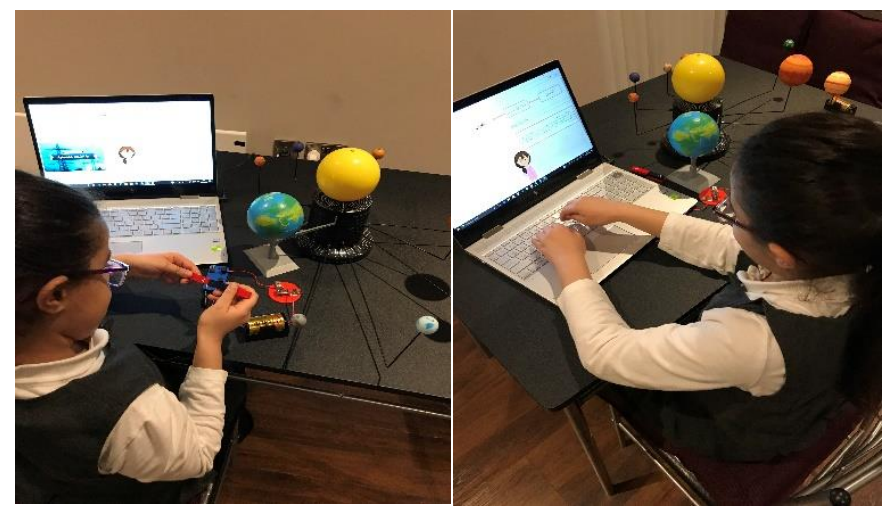

Fig. 4. The kinaesthetic learner interacts with the tutorial using physical model.

Dana was very interested when using LANA CITS and during the tutorial she was saying comments with positive words such as 'nice', I like it', 'I know the answer'. She was very excited when she used the magnetism model and the electric circuit during the tutorial. She was using LANA CITS independently and easily with no additional support once she was told in how to use it. She made a good improvement on her learning gain based on her scores in pre-test and post-test (Table 3). The posttest score was greater than the pre-test score. When she was asked in the interview if she can remember the tutorial, she said that she remembered it and recalled information about the tutorial. She said that she preferred to learn from LANA more than from her teacher. The rest of the questions were answered positively.

TABLE III. THE PRE-TEST AND POST-TEST SCORES FOR THE THREE PARTICIPANTS.

\begin{tabular}{|c|c|c|}
\hline Student's Name & $\begin{array}{c}\text { Pre-Test } \\
\text { (out of 10) }\end{array}$ & $\begin{array}{c}\text { Post-Test } \\
\text { (out of 10) }\end{array}$ \\
\hline Mariam & 4 & 9 \\
\hline Fatimah & 5 & 10 \\
\hline Dana & 6 & 10 \\
\hline
\end{tabular}

\section{Teacher observations and suggestions}

During the experiment, the teacher was attending in order to observe the student and to note if there is any different in the student's interaction from the classroom teaching. The teacher reported that Mariam interacted positively with LANA CITS and her interaction with LANA was better than in the classroom. According to the teacher's comments, Mariam does not like to listen to the lesson in the classroom for more than 15 minutes, she feels bored and she starts to do another task. Whereas, during the experiment, Mariam spent 25 minutes and she completed the whole tutorial. With the second participant, the teacher said that Fatimah interacted with LANA better than in the classroom. Based on the teacher's comments, Fatimah feels sleepy in the classroom and sometimes she sleeps during the lessons, whereas in the experiment, Fatimah spent 30 minutes, she did not feel sleepy and she completed the whole 
tutorial. With the third participant, the teacher reported that Dana also interacted with LANA better than in the classroom because Dana likes learning from the computer more than learning from the teacher. The teacher indicated that the use of LANA CITS was beneficial for the autistic students. The teacher particularly liked idea of the using the student's learning style in the tutorial and this will meet the individual learning needs for the students with ASD. The teacher suggested that using LANA in the classroom would be beneficial because it will increase the students' independence and decreased their dependence on the teacher. For example, students with using LANA CITS will not need to wait for a teacher to explain the lesson and then the teacher can focus on other aspects such as the student's behaviour, and social skills.

\section{CONCLUSION AND FUTURE WORKS}

This paper outlined and detailed the case study that was used to evaluate the LANA CITS with three autistic students in a mainstream school in Saudi Arabia. The results from this study indicated that the three participants showed an improvement on their learning gain when comparing the scores of the pre-test and the post-test (Table 3). Overall, a few differences were noted in terms of their perception of learning from LANA more than learning from the teacher. One student said that she liked the learning from LANA more than the learning from the teacher and the second student answered 'Maybe' and the third said 'Both'. Based on the teacher observation, LANA CITS was beneficial for the autistic students and the student's interaction during the tutorial was more positive than their interaction in the classroom. The teacher reported that one student feels sleepy and the other feels boring all the time in the classroom, whereas when they used LANA they were very interested and excited, because many students with ASD enjoy the use of technology. Finally, the teacher indicated that using LANA in the classroom would be beneficial because it will increase the students' independence and decreased their dependence on the teacher. Based on these results, it can be concluded that there is enough evidence to support H1 (LANA CITS can support learning in autistic children).

Future work will need with larger number of autistic students in mainstream schools in order to provide a quantitative estimate of the effect of LANA CITS.

\section{REFERENCES}

[1] N. Bauminger-Zviely, S. Eden, M. Zancanaro, P. L. Weiss, and E. Gal, "Increasing social engagement in children with high-functioning autism spectrum disorder using collaborative technologies in the school environment," Autism, vol. 17, no. 3, pp. 317-339, 2013.

[2] J. Barnard, A. Prior, and D. Potter, "Autism and inclusion: Is it working," London: National Autistic Society, 2000.

[3] P. Davis, L. Florian, and M. Ainscow, Teaching strategies and approaches for pupils with special educational needs: A scoping study. DfES Publications, 2004.

[4] E. M. C. Gregor and E. Campbell, "The attitudes of teachers in Scotland to the integration of children with autism into mainstream schools," Autism, vol. 5, no. 2, pp. 189-207, 2001.

[5] K. Robertson, B. Chamberlain, and C. Kasari, "General education teachers' relationships with included students with autism," Journal of Autism and developmental disorders, vol. 33, no. 2, pp. 123-130, 2003.

[6] L. D’Elia, G. Valeri, F. Sonnino, I. Fontana, A. Mammone, and S. Vicari, "A longitudinal study of the TEACCH program in different settings: The potential benefits of low intensity intervention in preschool children with autism spectrum disorder," Journal of autism and developmental disorders, vol. 44, no. 3, pp. 615-626, 2014.

[7] S. M. Edelson, "Learning styles and autism," Center for the Study of Autism, Salem, Oregon. En http://www. autism. org/styles. html, 2000.

[8] A. Mackay, Motivation, ability and confidence building in people. Routledge, 2010.

[9] P. Miller, "Learning Styles: The Multimedia of the Mind. Research Report," 2001.

[10] B. Banire, N. Jomhari, and R. Ahmad, "Visual Hybrid Development Learning System (VHDLS) Framework for Children with Autism," Journal of Autism and Developmental Disorders, vol. 45, no. 10, pp. 30693084, 2015.

[11] C. O'Connell et al., Supporting Children with Autistic Spectrum Disorders. Routledge, 2013.

[12] K. Snyder, T. S. Higbee, and E. Dayton, "PRELIMINARY INVESTIGATION OF A VIDEO BASED STIMULUS PREFERENCE ASSESSMENT," Journal of Applied Behavior Analysis, vol. 45, no. 2, pp. 413-418, 2012.

[13] A. M. Lisle, "Assessing learning styles of adults with intellectual difficulties," Journal of Intellectual Disabilities, vol. 11, no. 1, pp. 23-45, 2007.

[14] K. D. Roberts, "Topic areas to consider when planning transition from high school to postsecondary education for students with autism spectrum disorders," Focus on Autism and Other Developmental Disabilities, vol. 25, no. 3, pp. 158-162, 2010.

[15] M. L. Diener, C. A. Wright, S. D. Wright, and L. L. Anderson, "Tapping into technical talent: using technology to facilitate personal, social, and vocational skills in youth with autism spectrum disorder (ASD)," in Technology and the treatment of children with autism Spectrum disorder: Springer, 2016, pp. 97-112.

[16] S. Panzavolta, "Virtual Reality as a Tool for Enhancing Learning in At-Risk Students and Increasing School Inclusion," in Handbook of Research on Collaborative Teaching Practice in Virtual Learning Environments: IGI Global, 2017, pp. 242-257.

[17] S. S. Aljameel, J. D. O'Shea, K. A. Crockett, and A. Latham, "A Review of Current Technology-Based Intervention for School Aged Children with Autism Spectrum Disorder," in Proceedings of SAI Intelligent Systems Conference, 2016, pp. 868-879: Springer.

[18] S. Bernardini, K. Porayska-Pomsta, and T. J. Smith, "ECHOES: An intelligent serious game for fostering 
social communication in children with autism," INFORMATION SCIENCES, vol. 264, pp. 41-60, 2014.

[19] G. Lorenzo, A. Lledó, J. Pomares, and R. Roig, "Design and application of an immersive virtual reality system to enhance emotional skills for children with autism spectrum disorders," Computers \& Education, vol. 98, pp. 192-205, 2016.

[20] K. Gillespie-Lynch, P. J. Brooks, C. Shane-Simpson, N. L. Gaggi, D. Sturm, and B. O. Ploog, "Selecting Computer-Mediated Interventions to Support the Social and Emotional Development of Individuals with Autism Spectrum Disorder," Special and Gifted Education: Concepts, Methodologies, Tools, and Applications: Concepts, Methodologies, Tools, and Applications, p. 32, 2016.

[21] H. M. Truong, "Integrating learning styles and adaptive e-learning system: Current developments, problems and opportunities," Computers in Human Behavior, vol. 55, pp. 1185-1193, 2016.

[22] S. Aljameel, J. O'Shea, K. Crocket, A. Lathem, and M. Kaleem, "LANA: An Arabic Conversational Intelligent Tutoring System for Children with ASD," ed: IEEE Transection on Learning Technologies, 2018.

[23] S. S. Aljameel, J. D. O'Shea, K. A. Crockett, A. Latham, and M. Kaleem, "Development of An Arabic Conversational Intelligent Tutoring System for Education of Children with ASD," in Computational Intelligence and Virtual Environments for Measurement Systems and Applications (CIVEMSA), 2017 IEEE International Conference on, 2017, pp. 24-29: IEEE.

[24] A. C. Graesser, P. Chipman, B. C. Haynes, and A. Olney, "AutoTutor: An intelligent tutoring system with mixed-initiative dialogue," IEEE Transactions on Education, vol. 48, no. 4, pp. 612-618, 2005.

[25] A. M. Latham, K. A. Crockett, D. A. McLean, B. Edmonds, and K. O'Shea, "Oscar: An intelligent conversational agent tutor to estimate learning styles," in Fuzzy Systems (FUZZ), 2010 IEEE International Conference on, 2010, pp. 1-8: IEEE.

[26] O. G. Alobaidi, K. A. Crockett, J. D. O'Shea, and T. M. Jarad, "Abdullah: An Intelligent Arabic Conversational Tutoring System for Modern Islamic Education," in Proceedings of the World Congress on Engineering, 2013, vol. 2.

[27] M. o. Education. (2017). Ministry of Education. Available: https://www.moe.gov.sa/en/Pages/default.aspx

[28] C. Marshall and G. Rossman, "The how of the study: Building the research design," Designing qualitative research, pp. 55-101, 2006.

[29] S. Kvale and S. Brinkmann, "Learning the craft of qualitative research interviewing," Thousands Oaks: Sage Publications, 2009.

[30] B. Byrne, "Qualitative interviewing," Researching society and culture, vol. 2, pp. 179-192, 2004.

[31] M. Q. Patton, Qualitative research. Wiley Online Library, 2005.
[32] S. Q. Qu and J. Dumay, "The qualitative research interview," Qualitative research in accounting \& management, vol. 8, no. 3, pp. 238-264, 2011.

[33] A. B. Kajornboon, "Using interviews as research instruments," E-journal for Research Teachers, vol. 2, no. 1, pp. 1-9, 2005.

[34] B. L. Berg, Methods for the social sciences. Pearson Education Inc, United States of America, 2004.

[35] O. Doody and M. Noonan, "Preparing and conducting interviews to collect data," Nurse researcher, vol. 20, no. 5, pp. 28-32, 2013.

[36] J. W. Creswell and J. D. Creswell, Research design: Qualitative, quantitative, and mixed methods approaches. Sage publications, 2017. 